\title{
Gleason Score 4
}

National Cancer Institute

\section{Source}

National Cancer Institute. Gleason Score 4. NCI Thesaurus. Code C28097.

A Gleason score that is relatively uncommon and indicates a low-grade prostatic adenocarcinoma. The score or sum is estimated by adding the most prevalent and the second most prevalent histopathologic pattern of the malignant infiltrate. 